\title{
COMPORTAMENTO GEOQUÍMICO DO FLÚOR EM ÁGUAS E SEDIMENTOS FLUVIAIS DA REGIÃO DE CERRO AZUL, ESTADO DO PARANÁ, BRASIL
}

\author{
MARIA J. ANDREAZZINI' ${ }^{1}$, BERNARDINO R. FIGUEIREDO ${ }^{1} \&$ OTAVIO A. B. LICHT ${ }^{2}$
}

\begin{abstract}
Resumo O flúor é um elemento essencial para a saúde do homem, embora o consumo de água com excesso deste elemento possa ocasionar problemas nos dentes e ossos (doença conhecida como fluorose). Em água potável, o teor máximo recomendado pela OMS é $1,5 \mathrm{mg} / \mathrm{L} \mathrm{F}^{-}$, variando principalmente com as condições climáticas. Vários depósitos de fluorita ocorrem no Vale do Ribeira (SP-PR), dando origem a áreas com concentrações anômalas para flúor, identificadas a partir de estudos anteriores de geoquímica de sedimentos fluviais e concentrados de bateia. Este trabalho analisou a qualidade das águas e sedimentos fluviais no município de Cerro Azul, onde estão localizados os depósitos Volta Grande e Mato Preto. Os parâmetros de qualidade das águas, como pH, Eh, condutividade, oxigênio dissolvido, temperatura, turbidez, TDS e alcalinidade, foram determinados in situ. Amostras de água filtrada $(<0,45 \mu \mathrm{m})$ foram analisadas por cromatografia iônica para ânions e por ICP-OES para cátions. As concentrações de $\mathrm{F}^{-}$em água foram determinadas por eletrodo de íon seletivo (EIS), obtendo-se concentrações de 0,07 até $2,54 \mathrm{mg} / \mathrm{L} \mathrm{F}^{-}$. Teores de F- superiores aos limites permitidos corresponderam às drenagens próximas ao depósito Mato Preto, onde também as concentrações de $\mathrm{Ca}^{2+}, \mathrm{Sr}^{2+}$ e $\mathrm{Ba}^{2+}$ em água foram as mais altas. Não obstante, a água utilizada para consumo das populações da área apresentou teores de $\mathrm{F}^{-}$inferiores ao limite estabelecido pela legislação. Na região ficou definida assim uma área de risco potencial para a população, localizada nas proximidades da jazida Mato Preto, onde é desaconselhável a utilização de água de rios para consumo humano. Correlações positivas do $\mathrm{F}$ com Si, $\mathrm{Ca}^{2+}, \mathrm{Li}^{+}$e $\mathrm{K}^{+}$nas águas superficiais permitiram inferir que o $\mathrm{F}^{-}$poderia provir da alteração de silicatos como biotita e hornblenda, e ainda da solubilização de fluorita. Adicionalmente, amostras de sedimentos fluviais foram analisadas nas frações $<177 \mu \mathrm{m} \mathrm{e}<63 \mu \mathrm{m}$ por fluorescência de raios X, e para flúor pelo método de fusão alcalina + EIS. Os teores de flúor situaram-se no intervalo 330-1300 $\mu \mathrm{g} / \mathrm{g}$, sendo em geral mais elevados na fração mais fina. Análises por difração de raios $\mathrm{X}$ e microscopia eletrônica de varredura permitiram inferir alguns dos minerais responsáveis pelo aporte de flúor aos sedimentos: micas (biotita), hornblenda, illita, esmectita, e também fluorita e apatita.
\end{abstract}

Palavras-chave: flúor, água superficial, sedimentos fluviais, Volta Grande, Mato Preto, Cerro Azul.

Abstract GEOCHEMICAL BEHAVIOR OF FLUORINE IN STREAM WATER AND SEDIMENTS IN THE CERRO AZUL REGION, PARANÁ STATE, BRAZIL. Fluorine is an essential element for human health, but consumption of water with $\mathrm{F}^{-}$in excess will cause adverse effects in teeth and bones (fluorosis). According to WHO, a maximum of $1,5 \mathrm{mg} / \mathrm{LF}^{-}$is recommended for drinking water, but this level may vary mainly according to local climatic conditions. Some fluorspar deposits are found in the Ribeira Valley (SP-PR) in certain anomalous areas for fluorine as shown in previous geochemical studies using stream sediments and pan concentrates. This work was conceived to assess the quality of surface waters and sediments in the Cerro Azul region, where the Volta Grande and the Mato Preto fluorspar deposits are known. The water quality parameters ( $\mathrm{pH}, \mathrm{Eh}$, electric conductivity, DO, temperature, turbidity and TDS) as well as alkalinity were measured in situ. Filtered $(<0.45 \mu \mathrm{m})$ water samples were analyzed by ionic chromatography for anions and by ICP-OES for cations. The fluorine contents were determined by ion selective electrode (ISE) yielding concentrations from 0.07 to $2.54 \mathrm{mg} / \mathrm{LF}^{-}$. The highest $\mathrm{F}^{-}$concentrations coincide with the Mato Preto deposit surrounding area and, these samples were also characterized by higher $\mathrm{Ca}^{2+}, \mathrm{Sr}^{2+}$ and $\mathrm{Ba}^{2+}$ contents in relation to those located far from the mine. Nevertheless, the water consumed by local population showed $\mathrm{F}^{-}$concentrations within the recommended limits. The hydrogeochemical results indicated in the area that surrounds the Mato Preto deposit, the surface waters used for human consumption, presents some risk for health and sanity. Positive correlations of $\mathrm{F}$ with $\mathrm{Si}, \mathrm{Ca}^{2+}, \mathrm{Li}^{+}$and $\mathrm{K}^{+}$in surface water allowed to infer that $\mathrm{F}^{-}$could be a result from the alteration of silicates such as biotite and hornblende, and even from the dissolution of fluorspar. Additionally, the bulk chemical compositions of river sediments were analyzed in the $<177 \mu \mathrm{m}$ and $<63 \mu \mathrm{m}$ fractions by XRF and, for fluorine content by the method of alkaline fusion + ISE. Concentrations of F vary in the interval 330 to $1300 \mu \mathrm{g} / \mathrm{g} \mathrm{F}$ and generally the highest values were obtained in the $<63 \mu \mathrm{m}$ fraction. X-ray diffraction and scanning electron microscopy analysis allowed infer some of the possible mineral phases that contribute with fluorine to the fluvial sediments: micas (biotite), hornblende, illite and smectite as well as fluorspar and apatite.

Keywords: fluorine, surface water, fluvial sediments, Volta Grande, Mato Preto, Cerro Azul

INTRODUÇÃO A relação entre concentração de fluoreto em águas e os efeitos adversos à saúde humana é uma das mais conhecidas em geologia médica. O flúor é considerado um elemento essencial para a saúde do homem, mas podem advir problemas de saúde dental e óssea por ingestão excessiva deste elemento.

Este estudo foi desenvolvido em uma área localizada no Alto Vale do Rio Ribeira, no nordeste do estado do Paraná, na região da cidade de Cerro Azul, onde se encontram os depósitos de fluorita de Volta Grande (VG) e Mato Preto (MP) (Fig. 1).

A fluorita é um mineral instável sob diversas condições de intemperismo, promovendo a liberação de flúor ao ambiente secundário. Com base em dados de sedimentos fluviais e concentrados de bateia, Licht et al. (1996a) delimitaram uma área anômala para flúor na região de Cerro Azul, coincidente com a ocorrência de vários depósitos de fluorita, e recomendaram a realização de pesquisas mais detalhadas sobre a disponibilidade do flúor nas águas superficiais para avaliar o risco de manifestação de fluorose na população. O presente estudo teve como objetivo avaliar a qualidade da água superficial e dos sedimentos fluviais em drenagens no município de Cerro Azul, Paraná, com vistas a identificar áreas de risco de exposição da população.

Flúor e Saúde Humana. A população pode estar exposta ao 


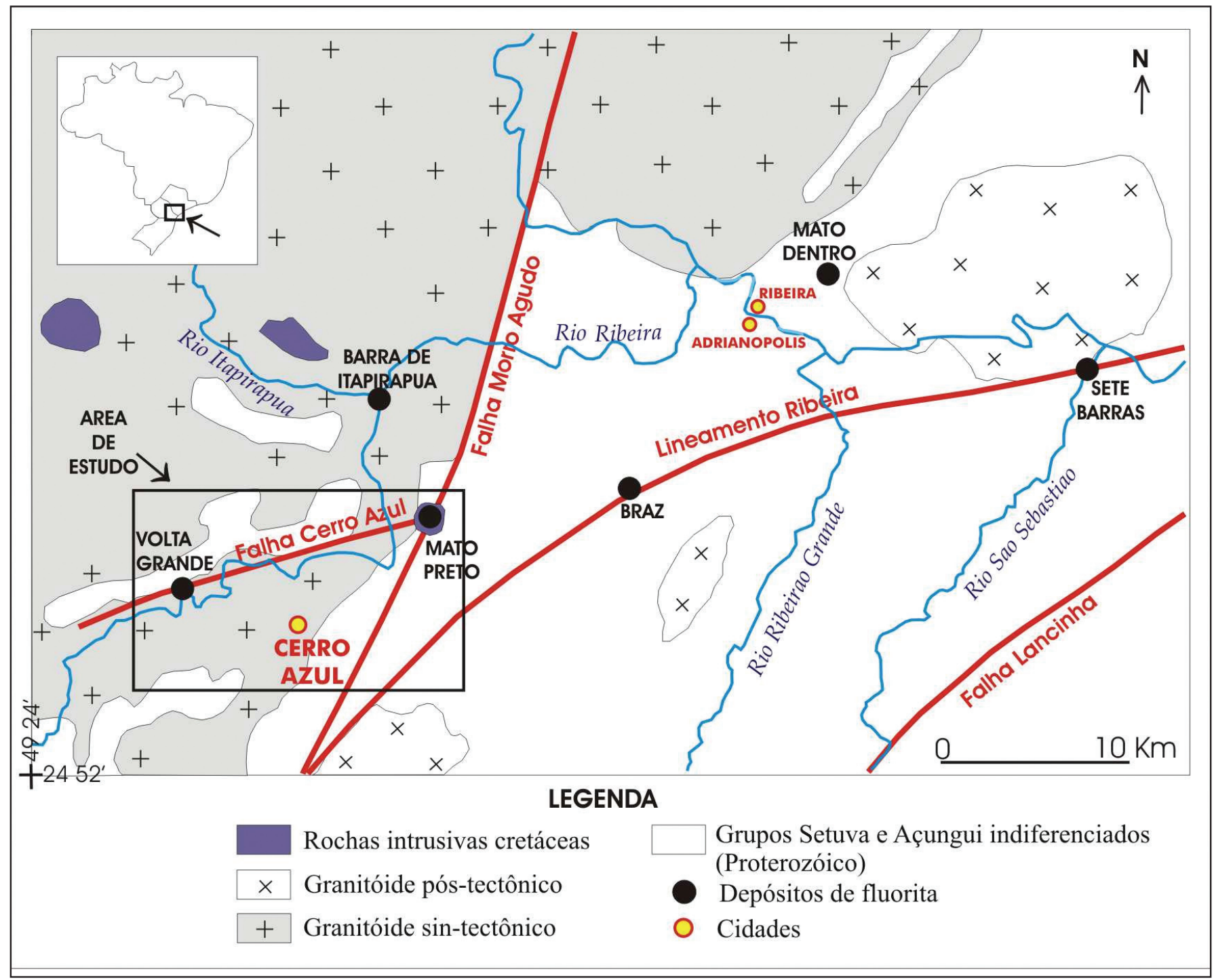

Figura 1. Localização da área de estudo e o ambiente geológico regional (Ronchi et al. 1995).

fluoreto através do ar, dos alimentos, de solos contaminados e pelo consumo de água, sendo esta última a principal via de intoxicação. O teor máximo de $\mathrm{F}^{-}$em água potável, recomendado pela OMS, é de $1,5 \mathrm{mg} / \mathrm{L}$, com variações admitidas principalmente em função da temperatura média anual da região $\left(18^{\circ} \mathrm{C}=\right.$ $1,2 \mathrm{mg} / \mathrm{L} ; 19-26^{\circ} \mathrm{C}=0,9 \mathrm{mg} / \mathrm{L} ; 27^{\circ} \mathrm{C}$ ou mais $\left.=0,7 \mathrm{mg} / \mathrm{L} \mathrm{F}^{-}\right)$. No Brasil, a Resolução CONAMA 020/86 estabelece um teor máximo aceitável de 1,4 mg/L F-, e a Portaria $\mathrm{N}^{\circ} 518$ da Agência Nacional de Vigilância Sanitária, de 1,5 mg/L F- para água potável (ANVISA, 2004). Especificamente para o estado de São Paulo, a Resolução SS-293/96 estabelece critérios de classificação da água distribuída pelos Sistemas de Abastecimento Público, e considera um conteúdo adequado de $\mathrm{F}^{-}$entre 0,6 e 0,8 mg/L.

De uma ingestão determinada de flúor, aproximadamente 80 \% é absorvido no estômago e intestino delgado, e o restante eliminado através das excreções. O flúor absorvido passa ao plasma sanguíneo e logo é distribuído aos diferentes tecidos. A afinidade dos tecidos calcificados pelo flúor é importante, determinando sua retenção persistente e acumulativa nos ossos, sendo maior nos organismos em crescimento (Ortiz Ruiz, 1997). As águas potáveis que contêm cerca de $1 \mathrm{mg} / \mathrm{L} \mathrm{F}^{-}$promovem uma redução significativa das cavidades dentárias, devidas à cárie, em crianças (ATSDR 2001). O flúor desempenha uma função remineralizadora, através de reações químicas na região mais superficial do esmalte. Se um nível razoável de íon $\mathrm{F}^{-}$está presente na dieta durante a fase de crescimento dos dentes, uma quantidade significativa de fluorapatita $\left(\mathrm{Ca}_{10}\left(\mathrm{PO}_{4}\right)_{6} \mathrm{~F}_{2}\right)$ é incorporada ao esmalte no lugar da hidroxiapatita $\left(\mathrm{Ca}_{10}\left(\mathrm{PO}_{4}\right)_{6}(\mathrm{OH})_{2}\right)$. A fluorapatita é menos solúvel nos ácidos do ambiente bucal, tornando os dentes menos susceptíveis às cáries. O flúor também desempenha uma função bacteriostática, já que quando presente no ambiente bucal inibe o sistema enzimático das bactérias, impedindo o desdobramento dos açúcares e a conseqüente formação de ácidos que atuam sobre o esmalte.

No entanto, quando o flúor é ingerido em excesso, durante o período de formação dos dentes, pode ocorrer uma intoxicação crônica e originar a fluorose dentária, uma patologia que se manifesta por meio de manchas esbranquiçadas a amarronzadas na superfície do esmalte dentário ou, até mesmo, por perdas em sua estrutura (Cardoso et al. 2001, UNICEF 2003). Já a fluorose esqueletal desenvolve endurecimento ou aumento anormal da densidade óssea em pessoas que ingerem, de forma continuada, teores maiores que $3 \mathrm{mg} / \mathrm{L} \mathrm{F}^{-}$. Os máximos efeitos adversos são detectados nas articulações do pescoço, costas, joelho, pélvis e ombros, e também são afetadas articulações das mãos e dos pés (Gupta \& Deshpande 1998). O tecido ósseo neoformado não tem a estrutura do tecido ósseo normal, originando um osso mais denso e menos elástico, o que o faz mais susceptível de ser 
fraturado (Ortiz Ruiz 1997).

Além desses efeitos, diferentes sintomas gastrointestinais decorrentes do uso crônico de flúor em concentrações de 1 ppm têm sido documentados. Entre eles estão náuseas, vômitos, dor abdominal e diarréia. O fluoreto combina-se com o $\mathrm{HCl}$ do estômago e converte-se em ácido hidrofluorídrico, altamente corrosivo (Gupta \& Deshpande 1998).

A fluorose é endêmica ao menos em 25 países no mundo. Somente na China, mais de 100 milhões de pessoas sofrem de fluorose, dentre elas 40 milhões afetadas por fluorose dentária e 2 a 3 milhões de fluorose esquelética. No México, cinco milhões de pessoas são afetadas por flúor em águas subterrâneas, consumindo água com teores acima de 1,5 mg/L F-. Em 1993, 15 dos 32 estados da Índia foram identificados como endêmicos para fluorose (UNICEF 2003). Elevadas concentrações de arsênio e flúor de origem natural nas águas subterrâneas constituem um problema que afeta também grandes extensões do norte e centro da Argentina. O flúor está associado aos níveis de sedimentos loéssicos quaternários (Bonorino et al. 2002, Warren et al. 2002, Blarasín et al. 2003).

Cangussu et al. (2002) realizaram uma compilação dos estudos feitos no Brasil (entre 1970 e 2000) sobre a prevalência e severidade da fluorose dentaria. Observaram prevalências de 0 até $97,6 \%$, com grande variabilidade de acordo com as regiões, e constataram que, mesmo com altas prevalências, a proporção de indivíduos que apresentam as formas moderada e severa ainda é pequena, só aumentando nos locais onde a fluorose é endêmica devido à alta concentração de fluoreto nas fontes naturais de água.

Vários casos de fluorose têm sido registrados em áreas mineralizadas com fluorita ou com indícios de mineralização. Tal é o caso das localidades de Mocambo e Boca do Mato, município de São Francisco, norte de Minas Gerais, onde os teores nas águas subterrâneas de algumas áreas variam entre 1,17 e 5,2 mg/ L F-(Meneasse et al., 2002). No município de São Francisco não são conhecidas jazidas de flúor, mas desenvolveram-se trabalhos prospectivos para fluorita e galena em áreas de ocorrência de rochas carbonáticas do Grupo Bambuí.

Diversos artigos (Licht et al. 1996b, Licht et al. 1997, Licht 2001) baseados no Levantamento Geoquímico Multielementar de Baixa Densidade do Paraná, delimitaram uma grande região fluoranômala na região do Norte Pioneiro do estado do Paraná, onde foram determinados teores de até $1,9 \mathrm{mg} / \mathrm{L}$ de $\mathrm{F}^{-}$em amostras de água. Na localidade de São Joaquim do Pontal, município de Itambaracá, a prevalência de fluorose dental encontrada na população em idade escolar foi de $72 \%$, sendo $61 \%$ com níveis 4 e 5 de severidade (Cardoso et al. 2001).

Uma outra forma de exposição ao flúor ocorre pela via inalatória. Finkelman et al. (1999) descrevem problemas de saúde gerados por elementos traço ou compostos orgânicos emitidos durante a combustão doméstica de carvão na China. O excesso de flúor é causado pelo uso de estufas para secar alimentos e aquecer as casas, as quais utilizam carvão e camadas de argila com altos teores de flúor.

Geoquímica do Flúor. Durante a evolução magmática o flúor geralmente ocorre como um componente característico da fase volátil, concentrando-se nas fases finais da evolução em rochas alcalinas, carbonatitos, depósitos hidrotermais, zonas de alteração e pegmatitos, geralmente como fluorita. Na natureza, o F é encontrado nos constituintes de rochas silicáticas, onde a apatita, $\mathrm{Ca}_{10}\left(\mathrm{PO}_{4}\right)_{6} \mathrm{~F}_{2}$, é um dos minerais mais ricos em flúor. Nos minerais formadores de rochas, o flúor é componente essencial só na fluorita $\left(\mathrm{CaF}_{2}\right)$ e no topázio $\left(\mathrm{Al}_{2} \mathrm{SiO}_{4}(\mathrm{OH}, \mathrm{F})_{2}\right)$. Também pode ser fixado em alguns hidroxi-silicatos e hidroxi-aluminosilicatos complexos, nos quais os íons hidroxilas $(\mathrm{OH})^{-}$podem ser substituídos por $\mathrm{F}^{-}$, como é o caso dos anfibólios, minerais do grupo das micas (especialmente biotita), e minerais de argila tais como illita, clorita e esmectita. Em geral, rochas ultramáficas (média 100 ppm F) e rochas intermediárias (400ppm F) têm um conteúdo de flúor menor que as rochas ricas em $\mathrm{SiO}_{2}$ (média 800 ppm F) (Goldschmidt 1970). O flúor liberado pelo intemperismo dos minerais passa às soluções aquosas superficiais na forma do íon fluoreto livre dissolvido $\left(\mathrm{F}^{-}\right)$, de alta mobilidade. A espécie HF é estável a $\mathrm{pH}$ baixos, e predominante a $\mathrm{pH}<3,5$ (Bell 1998). O conteúdo médio de $\mathrm{F}^{-}$na água do mar situa-se em 1-1,3 mg/L. Nas águas subterrâneas a concentração natural pode variar desde menos que 1 a mais de $35 \mathrm{mg} / \mathrm{L} \mathrm{F}^{-}$, enquanto que águas de rios e lagos geralmente apresentam concentrações baixas (0,01-0,3 mg/L) (UNICEF 2003). Águas de mananciais termais apresentam concentrações variadas, de menos que 1 a mais de $55 \mathrm{mg} / \mathrm{L} \mathrm{F}^{-}$. Em alguns casos, o conteúdo de $\mathrm{F}^{-}$nessas águas aumenta com a temperatura (Allmann \& Koritning 1972).

Os fatores mais importantes que controlam a concentração de $\mathrm{F}^{-}$nas águas naturais são temperatura, $\mathrm{pH}$, presença ou ausência de íons e colóides complexantes, solubilidade dos minerais que contêm flúor, capacidade de troca iônica dos materiais do aqüífero $\left(\mathrm{OH}^{-}\right.$por $\left.\mathrm{F}^{-}\right)$, e tamanho e tipo de formações geológicas percoladas pelas águas (Apambire et al. 1997).

A fluorita é um mineral instável em diversas condições de intemperismo, oxidantes ou redutoras, ácidas ou alcalinas, o que promove a liberação de flúor para o ambiente secundário em regiões ricas nesse mineral (Andrews-Jones 1968). A concentração de $\mathrm{F}^{-}$em água está limitada pela solubilidade da fluorita. Seu baixo produto de solubilidade $\left(3.9 \times 10^{-11}\right.$ a $\left.20{ }^{\circ} \mathrm{C}\right)$, implica que águas com baixo conteúdo em cálcio poderiam ter altas concentrações de flúor (Bell 1998; Hurtado et al. 2002). A concentração de $\mathrm{F}^{-}$em águas subterrâneas também aumenta onde ocorre intercambio catiônico de $\mathrm{Ca}^{2+}$ por $\mathrm{Na}^{+}$, diminuindo assim a concentração de $\mathrm{Ca}^{2+}$ na água e potencializando a mobilidade dos fluoretos (Bell, F. 1998).

Contexto Geológico da Área de Estudo. No Vale do Ribeira existem pelo menos seis áreas com mineralização de fluorita. A região é afetada por zonas de cisalhamento transcorrentes regionais e os depósitos estão semi-alinhados ao longo de $50 \mathrm{~km}$ segundo uma direção E-NE (Fig. 1). Os depósitos de Volta Grande (VG), Sete Barras e Mato Dentro são, de forma geral, concordantes com a estratificação das rochas metacarbonatadas encaixantes. Mato Preto (MP) é um grande depósito associado a um complexo de rochas alcalinas e carbonatitos, Barra de Itapirapuã é uma acumulação não econômica disseminada num carbonatito e, finalmente, o depósito não econômico do Braz corresponde a preenchimento de fraturas (Dardenne et al. 1997). A mina de MP é a única atualmente em atividade na região.

As unidades litológicas do Vale do Ribeira fazem parte de um cinturão móvel Proterozóico de direção NE, constituído por um domínio Leste (Complexo Costeiro), formado por gnaisses arqueanos, migmatitos e granulitos retrabalhados no Proterozóico Superior, e um domínio Oeste (cinturão dobrado Apiaí) que inclui seqüências vulcano-sedimentares Proterozóicas metamórficas de baixo a médio grau, e um pequeno domínio de rochas arqueanas, esse último parcialmente coberto pela seqüência sedimentar fanerozóica da Bacia do Paraná. A culminação metamórfica ocorreu entre os 600 e $700 \mathrm{Ma}$ (Hasui et al. 1984) e ambos domínios foram intrudidos por granitóides sintectônicos (Granito Três Córregos) e postectônicos (Granito Itaóca) durante o ciclo orogênico Brasiliano (450-700 Ma) (Ronchi et al. 1995).

Durante o Mesozóico, intenso vulcanismo fissural de natureza básica, relacionado aos derrames da bacia do Paraná, manifesta-se como diques de diabásio do Jurássico, de direção geral 
$\mathrm{N} 45^{\circ} \mathrm{E}$, e no Cretáceo ocorre o posicionamento de intrusões de natureza alcalina-carbonatíticas, às vezes mineralizadas a $\mathrm{Fe}, \mathrm{F}$, $\mathrm{P}$ e ETR. As formações sedimentares fanerozóicas da Bacia do Paraná, protegeram o cinturão móvel proterozóico até o levantamento terciário, quando então ocorreram os processos erosivos que expuseram as rochas do embasamento (Ronchi et al. 1995).

Depósito Volta Grande. A mineralização de fluorita de VG está encaixada em enclaves de rochas carbonáticas (com direção geral E-O e mergulhos $50-70^{\circ} \mathrm{N}$ ) dentro do granito Três Córregos. As rochas carbonáticas do enclave são cálcio-dolomitos impuros, compostos por calcita, dolomita, ortoclásio, quartzo e opacos. Estas rochas foram afetadas por processos de substituição por fluorita e sílica, restando entretanto porções de mármore não mineralizadas, zonas de transição mármore-minério, além do minério que foi substituído por sílica e carbonato (Ronchi et al. 1987). O granito porfiróide Três Córregos possui fenocristais de microclínio ou ortoclásio, e a matriz granular composta por oligoclásio-andesina, quartzo, microclínio, hornblenda, biotita e opacos. Acessoriamente ocorrem apatita, titanita, zircão e turmalina.

O depósito está formado por três corpos principais (corpos I, II e III), que somam $460 \mathrm{~m}$ de comprimento, variam entre 5 e $20 \mathrm{~m}$ de espessura e chegam a atingir até $120 \mathrm{~m}$ de profundidade (Ronchi et al. 1995). As reservas estão estimadas em 1,1 Mt de minério, com 35-40\% de $\mathrm{CaF}_{2}$. O minério é essencialmente composto por fluorita e quartzo, podendo conter ainda calcita, dolomita, pirita e micas (muscovita e biotita), sendo comum a presença de barita e adulária (Dardenne et al. 1997). Na área também existem outras ocorrências não econômicas de fluorita e barita. Esta última concentra-se em bolsões e filonetes ao oeste do corpo I, e em uma faixa de $30 \mathrm{~m}$ de comprimento e espessura média de 1,5 $\mathrm{m}$ no corpo II.

Depósito Mato Preto. O complexo alcalino-carbonatítico de MP localiza-se às margens dos rios Pinheirinho e Mato Preto, afluentes do rio Ribeira. Apresenta uma reserva de 2,16 Mt de minério com teor médio de $60 \%$ de $\mathrm{CaF}_{2}$ (Jenkins 1987). O complexo situa-se ao longo da Zona de Falha de Morro Agudo, a qual marca o contato entre as rochas metassedimentares do Grupo Açungui e o Granito Três Córregos. O complexo tem aproximadamente $24 \mathrm{~km}^{2}$ e exibe quatro estruturas circulares principais, cada uma com cerca de $1 \mathrm{~km}$ de diâmetro. As estruturas são circundadas por rochas graníticas e metassedimentares que se encontram afetadas pelo metassomatismo alcalino (Santos \& Dardenne 1988).

O Grupo Açungui está representado no local, principalmente por metassedimentos síltico-argilosos e carbonáticos, de idade Proterozóica Média a Superior. Várias fases de magmatismo alcalino se alternaram na formação do complexo, e fenômenos tardi-magmáticos foram responsáveis por processos de silicificação e enriquecimento em fluorita. As rochas alcalinas de Mato Preto são consideradas de idade Cretácea, representadas principalmente por carbonatitos, sienitos nefelínicos e fonólitos. Formam um pequeno stock alongado no sentido E-W (Mattos 1989).

$\mathrm{Na}$ parte central noroeste do complexo existe o maior volume de carbonatitos, com enriquecimento local em fluorita e sulfetos (Loureiro \& Tavares 1983). A maior concentração de fluorita situa-se no depósito Clugger, localizado numa estrutura circular. A fluorita ocorre em quatro corpos lenticulares de direção N 50-60 $\mathrm{E}$, com mergulho de $80-85^{\circ} \mathrm{NO}$. As lentes são sub-paralelas e medem aproximadamente $250 \mathrm{~m}$ de comprimento e $80 \mathrm{~m}$ de espessura, sendo atingidas por sondagens até cerca de $120 \mathrm{~m}$ de profundidade (Jenkins 1987). A atividade geradora da fase carbonatítica promoveu a concentração de vários elementos. Além da fluorita, no depósito são conhecidas concentrações e/ou áreas enriquecidas em magnetita, apatita, pirita, bornita, terras raras, nióbio, tório, zircônio, titânio e urânio (Loureiro \& Tavares 1983).

MATERIAIS E MÉTODOS Amostras de água superficial foram coletadas em 18 estações em duas campanhas (julho de 2003 e março de 2004), e duas amostras de água subterrânea foram coletadas nas proximidades da cidade de Cerro Azul. Também foram coletadas amostras da água fornecida pela Companhia de Saneamento do Paraná (SANEPAR) para consumo da população da cidade de Cerro Azul, e de uma nascente que abastece o povoado de Mato Preto. Durante a coleta, os parâmetros físico-químicos ( $\mathrm{pH}, \mathrm{Eh}$, condutividade, oxigênio dissolvido, temperatura, turbidez, TDS) foram medidos in situ. No mesmo dia da coleta foram realizadas as análises de alcalinidade em amostras não filtradas, pelo método de titulação, utilizando 4 gotas do corante azul de bromocresol e $\mathrm{H}_{2} \mathrm{SO}_{4} 0,16 \mathrm{~N}$. As amostras para análises de cátions foram acidificadas com 4 gotas de $\mathrm{HNO}_{3}$ concentrado em $50 \mathrm{ml}$ de amostra. As amostras de água filtrada (Millipore $<0,45 \mu \mathrm{m}$ ) foram analisadas no Laboratório de Analises Minerais (LAMIN), os ânions $\mathrm{Cl}^{-}, \mathrm{NO}_{2}^{-}, \mathrm{Br}^{-}, \mathrm{NO}_{3}^{-}$, $\mathrm{PO}_{4}^{-3} \mathrm{e} \mathrm{SO}_{4}^{-2}$ por cromatografia iônica e os cátions Al, As, B, Ba, $\mathrm{Be}, \mathrm{Ca}, \mathrm{Cd}, \mathrm{Co}, \mathrm{Cr}, \mathrm{Cu}, \mathrm{Fe}, \mathrm{Li}, \mathrm{Mg}, \mathrm{Mn}, \mathrm{Mo}, \mathrm{Ni}, \mathrm{Pb}, \mathrm{Sc}, \mathrm{Se}, \mathrm{Si}$, $\mathrm{Sn}, \mathrm{Sr}, \mathrm{Ti}, \mathrm{V}, \mathrm{W}$ e Zn, por ICP-OES. Na e K foram analisados por espectrofotometria de absorção atômica.

Os conteúdos de $\mathrm{F}^{-}$foram determinados no Instituto de Geociências da Unicamp em um eletrodo de íon seletivo (EIS) marca Orion, modelo 96-09. A curva para a calibração do eletrodo foi realizada a partir de três soluções de referência, cada uma delas preparada com $5 \mathrm{ml}$ de solução TISAB III, e $50 \mathrm{ml}$ de soluções padrão de $0,1,1$ e $10 \mathrm{mg} / \mathrm{L}$ de $\mathrm{F}^{-}$, respectivamente. Para determinar o $\mathrm{F}^{-}$, foram colocados $50 \mathrm{ml}$ da amostra de água filtrada e $5 \mathrm{ml}$ de solução TISAB III, sempre utilizando copos béquer de plástico.

Nas mesmas campanhas também foram coletadas 14 amostras de sedimentos de corrente (12 em julho e 2 em março), as quais foram analisadas para 30 elementos nas frações granulométricas $<177 \mu \mathrm{m}$ e $<63 \mu \mathrm{m}$, por FRX também no IG da Unicamp, usando pastilhas de pó prensado. O controle de qualidade dos resultados, em termos de exatidão, foi efetuado pela análise simultânea de materiais de referência internacionais, amostras GSD-12 e GSD-9 (sedimentos de drenagem), e GSS-2 (solo), do IGGE IRMA da China. Nos materiais de referência analisados, os resultados dos elementos-traço e menores encontram-se dentro do intervalo do valor certificado \pm dois desvios padrão, enquanto para elementos maiores os resultados encontram-se dentro dos critérios sugeridos pelo IGCP (Darnley, 1995).

Os teores de flúor nas amostras de sedimentos foram determinados seguindo o procedimento proposto por Hopkins (1977), que basicamente consiste na fusão da amostra com uma mistura de $\mathrm{Na}_{2} \mathrm{CO}_{3}$ e $\mathrm{K}_{2} \mathrm{CO}_{3}$, seguida de adição de ácido cítrico e de uma soluçã̃o tampão de citrato de sódio, e, finalmente, medição do

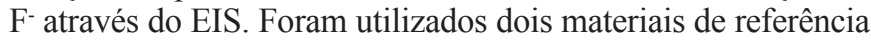
para controle das análises do flúor (GSD-2 e GSD-6, sedimentos de drenagem, do IGGE IRMA da China), obtendo-se resultados dentro dos limites aceitáveis.

Para determinar a composição mineralógica dos sedimentos foram feitas análises por DRX nas amostras de sedimentos (fração $<177 \mu \mathrm{m}$ ) no Laboratório de Raios X do Centro de Geociências da Universidade Federal do Pará. Para algumas destas amostras foi realizada a separação dos minerais densos utilizando bromofórmio, e foi feita novamente a análise difratométrica da fração de minerais densos. Algumas das amostras foram analisadas para a fração argila (amostra orientada, glicolada e aquecida). Observações complementares foram feitas utilizando microscópio eletrônico de varredura (MEV). 
Os resultados das análises de água superficial de cada coleta, foram usados na construção de matrizes de correlação com a finalidade de examinar possíveis correlações entre o $\mathrm{F}$ e os diferentes elementos. Os dados originais das variáveis analisadas (íons determinados pelas analises químicas) foram transformados nos seus logaritmos naturais ( $\mathrm{Ln}$ ), e todas as correlações foram calculadas para um nível de significância de $95 \%(\alpha=0,05$, valor crítico do coeficiente de correlação r).

\section{RESULTADOS E DISCUSÃO}

Qualidade das águas. Os parâmetros físico-químicos e os diferentes íons analisados para as águas da região de Cerro Azul, entre eles, elementos que representam risco para a saúde, foram comparados com os valores máximos permitidos pela Portaria N 518 da Agência Nacional de Vigilância Sanitária (ANVISA, 2004). A maior parte das águas analisadas encontram-se dentro dos padrões de potabilidade após tratamento convencional. As concentrações de $\mathrm{Be}, \mathrm{Cd}, \mathrm{Co}, \mathrm{Cr}, \mathrm{Cu}, \mathrm{Ni}, \mathrm{Pb}, \mathrm{Sc}, \mathrm{Se}, \mathrm{Sn}, \mathrm{Ti}, \mathrm{W}$ e $\mathrm{V}$ estiveram abaixo dos respectivos limites de detecção em todas as amostras. A amostra 12 apresentou, para a coleta de março/04, um teor de Fe de 0,311 mg/L (superior ao permitido pela legislação, que é $0,3 \mathrm{mg} / \mathrm{L}$ ). Foram detectados problemas com teores de flúor superiores aos limites permitidos nas drenagens próximas à mina de MP (Tabela 1 e Fig. 2).

$\mathrm{Na}$ Tabela 1 estão apresentados também os valores de $\mathrm{pH}$ e Eh medidos em cada estação de coleta. Para as amostras de água superficial, os valores de $\mathrm{pH}$ estiveram entre 7,3 e 8 na coleta de julho/03, e entre 7,7 e 8,3 na de março/04. Os valores de Eh situaram-se nos intervalos $452-532 \mathrm{mV}$ em julho/03 e 444-502 $\mathrm{mV}$, em março/04.

Os demais parâmetros de qualidade de água apresentaram variações, respectivamente nas duas ocasiões de coleta, como segue: condutividade elétrica nos intervalos $0,06-0,21 \mathrm{mS} / \mathrm{m}$ e 0,10-0,34 mS/m; OD 8,1-10,3 mg/L e 7,8-10,1 mg/L; temperatura $14,7-18,5^{\circ} \mathrm{C}$ e $21,1-27,8^{\circ} \mathrm{C}$. Durante a coleta de março, as concentrações totais de sólidos dissolvidos (TDS) variaram de 0,06 e $0,22 \mathrm{~g} / \mathrm{L}$, e os valores de turbidez entre 2 e 45 UTN.

Essas amostras de água, como indicado no diagrama de Piper, exibem composições coincidentes com águas bicarbonatadas cálcicas. Só a amostra 24 (água subterrânea) caiu no

Tabela 1. Concentrações de $F^{-}$e valores de pH e Eh nas amostras de água.

\begin{tabular}{|c|c|c|c|c|c|c|}
\hline \multirow[b]{2}{*}{ Amostra } & \multicolumn{2}{|c|}{$F^{-}$(mg/L) } & \multicolumn{2}{|c|}{ PH } & \multicolumn{2}{|c|}{ Eh } \\
\hline & julho/03 & março/04 & julho/03 & março/04 & julho/03 & março/04 \\
\hline 1 & 0,08 & 0,09 & 7,4 & 8,0 & 462 & 477 \\
\hline 2 & 0,09 & 0,09 & 7,5 & 8,0 & 528 & 469 \\
\hline 3 & 0,12 & 0,18 & 7,3 & 8,3 & 512 & 444 \\
\hline 4 & 0,28 & 0,46 & 7,7 & 8,0 & 511 & 491 \\
\hline $6^{*}$ & 0,84 & NA & 6,1 & NA & 861 & NA \\
\hline 7 & 0,11 & 0,12 & 7,4 & 8,1 & 532 & 492 \\
\hline 8 & 0,07 & 0,07 & 7,8 & 8,2 & 492 & 497 \\
\hline 9 & 0,08 & 0,09 & 7,5 & 8,0 & 502 & 502 \\
\hline 10 & 0,19 & 0,18 & 8,0 & 8,1 & 478 & 495 \\
\hline 11 & 0,07 & 0,07 & 7,8 & 8,0 & 463 & 496 \\
\hline 12 & 0,12 & 0,14 & 7,9 & 7,7 & 473 & 461 \\
\hline 13 & 0,18 & 0,27 & 7,7 & 8,2 & 462 & 444 \\
\hline 14 & 0,92 & 0,74 & 7,6 & 8,3 & 461 & 458 \\
\hline 15 & 1,72 & 2,54 & 7,9 & 8,1 & 462 & 465 \\
\hline 16 & 0,23 & 0,29 & 7,7 & 8,2 & 454 & 454 \\
\hline 17 & 0,10 & NA & 7,9 & NA & 461 & NA \\
\hline 18 & 0,10 & 0,10 & 7,4 & 8,3 & 462 & 472 \\
\hline 19 & 0,11 & 0,14 & 7,8 & 8,2 & 452 & 465 \\
\hline 20 & 0,09 & 0,09 & 7,6 & 8,2 & 472 & 469 \\
\hline 21 & NA & 0,73 & N.A. & 8,1 & NA & 476 \\
\hline $22^{*}$ & NA & 0,23 & NA & 7,6 & NA & 496 \\
\hline $23^{* *}$ & NA & 1,13 & NA & 6,1 & NA & 556 \\
\hline $24^{* *}$ & NA & 0,33 & NA & 6,4 & NA & 560 \\
\hline $25^{*}$ & NA & 1,02 & NA & 6,7 & NA & 842 \\
\hline
\end{tabular}




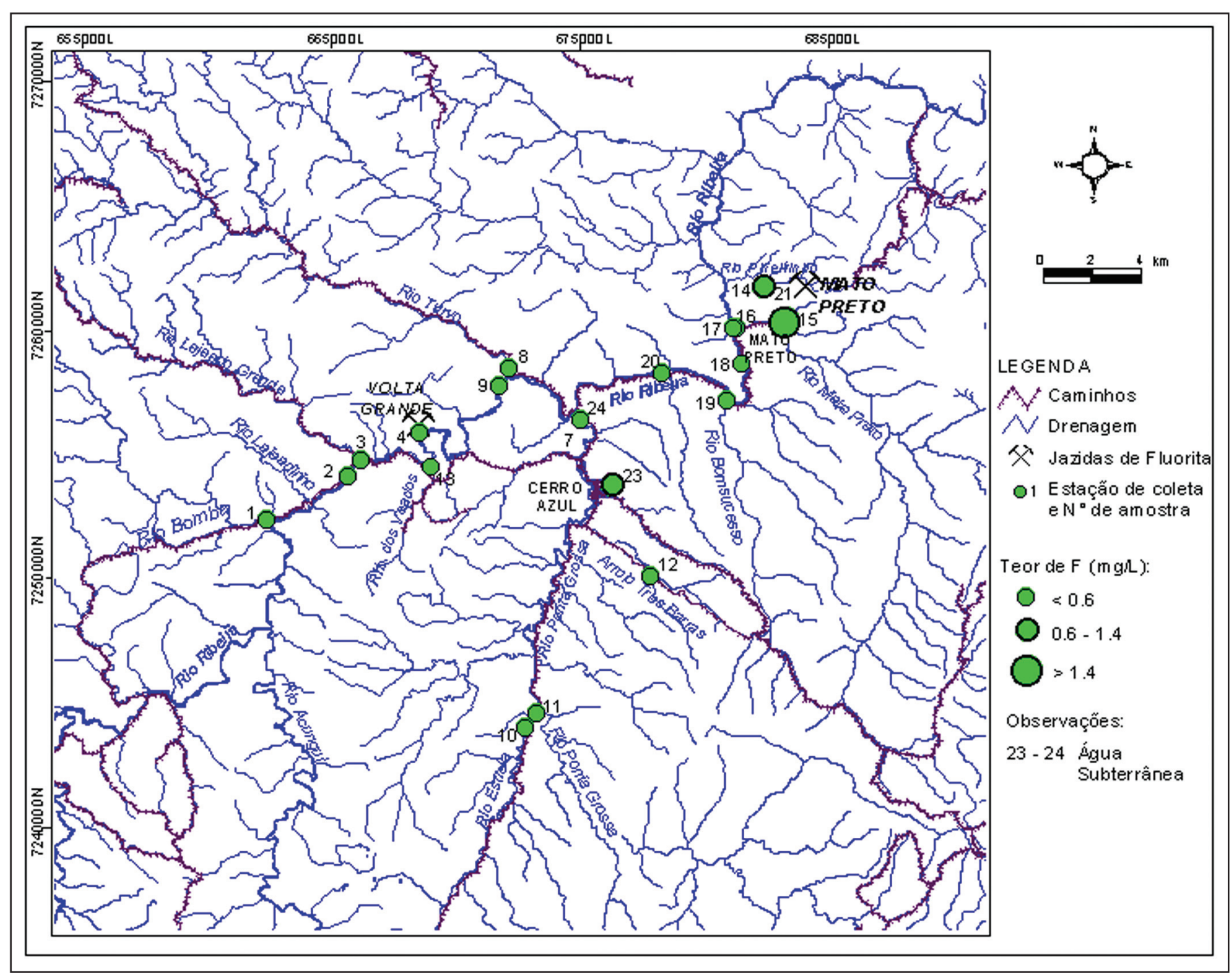

Figura 2. Mapa de teores de fluoreto em água superficial.

limite entre os campos de águas bicarbonatadas cálcicas e bicarbonatadas sódicas (Fig. 3). O diagrama triangular para cátions permite observar que as amostras próximas aos depósitos de fluorita ficaram dentro do campo das águas cálcicas, e as demais amostras representam águas mistas. Por outra parte, o triangulo para os ânions mostra que na totalidade das amostras domina o íon bicarbonato, estando em muito baixas concentrações os íons cloreto e sulfato.

As concentrações de flúor em água variaram de 0,07 até 2,54 $\mathrm{mg} / \mathrm{L} \mathrm{F}^{-}$, e os valores mais elevados corresponderam às amostras localizadas em cursos influenciados pelas duas mineralizações. Cabe destacar aqui que na amostragem de julho/03, planejada para representar o período seco na região, ocorreram intensas chuvas no dia anterior à coleta, o que gerou a diluição das amostras de água. Portanto, não foi possível determinar os máximos teores de $\mathrm{F}^{-}$nas águas da região, ficando a possibilidade de que algum outro curso de água exceda o limite permitido, por exemplo o rio Pinheirinho, onde a concentração de $\mathrm{F}^{-}$esteve próxima desse limite.

Para ambas coletas, aquelas amostras com maiores teores de $\mathrm{F}^{-}$apresentaram também concentrações mais elevadas de $\mathrm{Ca}^{2+}$, $\mathrm{Sr}^{2+}$ e $\mathrm{Ba}^{2+}$, elementos com afinidade geoquímica presentes em rochas carbonáticas e carbonatitos, enquanto os teores mais altos de $\mathrm{F}^{-}$nem sempre coincidiram com os maiores de $\mathrm{Si}^{+4}$ (Fig. 4). As amostras com alto teor de $\mathrm{F}^{-}$também se associaram com os mais baixos teores de Fe, nas drenagens sobre rochas carbonáticas de VG e alcalinas de MP (Fig.4). A amostra 13 (com 0,18 e 0,27 mg/ L F'), no entanto, apresentou teores elevados de Fe, que podem provir da alteração de minerais das rochas graníticas, tais como biotita e hornblenda. A amostra 15 destacou-se por uma concentração maior dos íons $\mathrm{SO}_{4}^{2-}$ e $\mathrm{PO}_{4}^{3-}$, relacionados a minerais como apatita e sulfetos presentes na mineralização de MP.

Nas amostras de água subterrânea (ambas localizadas dentro do ambiente granítico, na área próxima à cidade de Cerro Azul) foram determinados teores de 1,13 e 0,33 mg/L F-

A captação de água realizada pela empresa SANEPAR para posterior tratamento e distribuição à população de Cerro Azul está localizada no arroio Três Barras, onde foi coletada a amostra 12 que apresentou 0,12 e $0,14 \mathrm{mg} / \mathrm{L} \mathrm{F}^{-}$nas coletas de julho e março, respectivamente. Os teores de $\mathrm{F}^{-}$obtidos nas amostras de água já tratada para consumo das populações foram de 0,84 e 1,02 mg/L $\mathrm{F}^{-}$para cidade de Cerro Azul, em julho e março, respectivamente, e de $0,23 \mathrm{mg} / \mathrm{L} \mathrm{F}^{-}$para o povoado de Mato Preto em março. Em Cerro Azul é realizada a fluoretação das águas para levar o teor de fluoreto ao teor ótimo para consumo humano.

Análise estatística dos resultados de água superficial. Os cálculos de correlação de $\mathrm{F}^{-}$com os demais elementos mostraram, em alguns casos, uma falsa correlação, induzida pelos valores anômalos de F-. Por esse motivo, as correlações foram cal- 


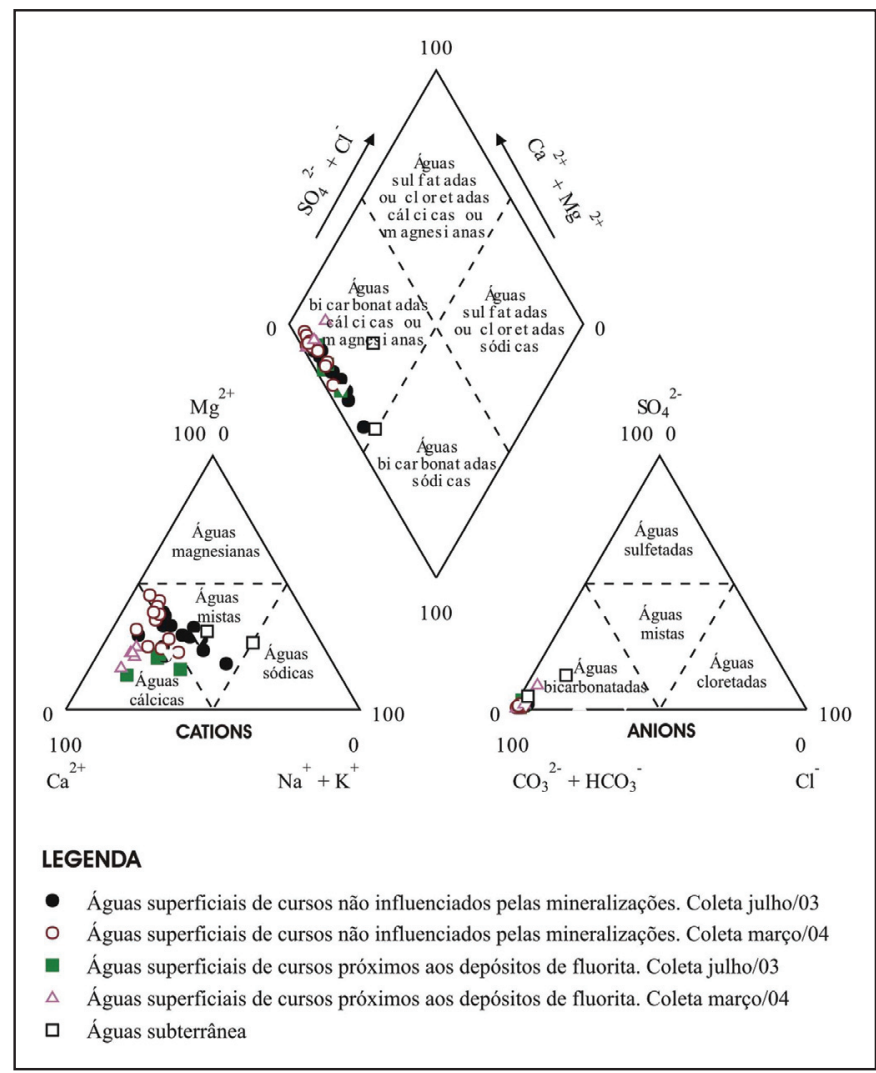

Figura 3. Diagrama de Piper para as amostras de água.

culadas excluindo as amostras com altos teores de $\mathrm{F}^{-}$, resultando uma população com $\mathrm{N}=12$.

Para os dados de julho/03, foram obtidas correlações positivas de $\mathrm{F}^{-}$com $\mathrm{Si}^{4+}, \mathrm{Na}^{+}$e $\mathrm{Mn}$, e negativa de $\mathrm{F}^{-}$com $\mathrm{Mg}^{2+}$ (Fig. 5). Por outro lado, considerando-se os dados de março/04, foram

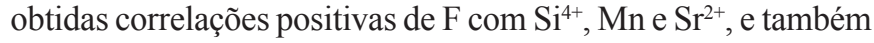
negativa do $\mathrm{F}^{-}$com $\mathrm{Mg}^{2+}$ (Fig. 6).

A correlação positiva do $\mathrm{F}^{-}$com $\mathrm{Si}^{4+}$ nas águas superficiais não influenciadas pela mineralização, pode estar indicando um aporte de flúor a partir da alteração de silicatos (anfibólios, biotitas).

A correlação positiva do $\mathrm{F}^{-}$com $\mathrm{Sr}^{2+}$ indicaria a associação destes dois elementos com fluorita, principalmente, e provável substituição de cálcio por estrôncio em carbonatos. As correlações positivas de $\mathrm{F}^{-}$com $\mathrm{Li}^{+}$e $\mathrm{K}^{+}$nas águas estariam indicando também a associação da mineralização com rochas alcalinas. A correlação positiva $\mathrm{F}^{-} \mathrm{Na}^{+}$, também tem sido citada na bibliografia. Pelo processo de troca iônica o conteúdo de $\mathrm{Na}^{+}$aumenta nas águas enquanto o de $\mathrm{Ca}^{2+}$ diminui favorecendo o aumento da concentração de $\mathrm{F}^{-}$nas mesmas (Bell, F. 1998).

$\mathrm{Na}$ literatura é citada uma correlação negativa entre $\mathrm{F}^{-}$e $\mathrm{Ca}^{2+}$ em águas subterrâneas (Apambire et al., 1997), mas para as águas superficiais analisadas neste trabalho não foi observada tal correlação. Pelo contrario, a correlação positiva encontrada entre estes dois elementos (neste caso considerando a totalidade das amostras, para ambas coletas) pode indicar contribuição de outras fontes do $\mathrm{F}^{-}$nas águas como fluorita, anfibólios e biotita.

Análises dos sedimentos fluviais. As amostras de sedimentos apresentaram teores de F entre 330 e $1300 \mu \mathrm{g} / \mathrm{g}$ (Tabela 2). Em geral, as concentrações de $F$ na fração $<63 \mu \mathrm{m}$ são mais altas que na fração $<177 \mu \mathrm{m}$, à exceção das amostras das cercanias da jazida Mato Preto (15a e 15b), dada sua proximidade à fonte e a menor distância de transporte a que foram submetidas. Destaca-se também que para algumas amostras a diferença entre os teores determinados para as duas frações encontra-se dentro do erro analítico do método.

Os resultados obtidos por FRX mostraram que a composição química dos sedimentos de drenagem reflete a mineralogia dos litotipos principais da região (rochas graníticas, metassedimentares, e o complexo alcalino-carbonatítico). Teores mais altos de $\mathrm{CaO}$ corresponderam aos sedimentos de cursos que drenam rochas carbonáticas. No ambiente granítico, os sedimentos apresentaram baixos teores de $\mathrm{MnO}$ e $\mathrm{FeO}^{\mathrm{T}}$ (possivelmente indicando que houve perda durante a alteração de minerais como biotitas e anfibólios), e altos de $\mathrm{Na}_{2} \mathrm{O}$ e $\mathrm{K}_{2} \mathrm{O}$ (correspondentes aos feldspatos e micas). Sedimentos coletados sobre carbonatitos, rochas alcalinas e rochas metassedimentares mostraram baixos teores de $\mathrm{Na}_{2} \mathrm{O}$ e $\mathrm{K}_{2} \mathrm{O}$, e elevados de $\mathrm{FeO}^{\mathrm{T}}$ e $\mathrm{MnO}$ (estes últimos representando óxidos), com relação às demais amostras.

Nas áreas mineralizadas, os sedimentos de Volta Grande, em geral, mostraram altos teores de $\mathrm{CaO}, \mathrm{MgO}, \mathrm{MnO}, \mathrm{F}, \mathrm{Sr}, \mathrm{Ba}$, Th, $\mathrm{Rb}, \mathrm{Y}, \mathrm{Pb}$ e $\mathrm{P}_{2} \mathrm{O}_{5}$ (este último na fração mais fina), associados à fluorita, carbonatos, sulfatos (barita), sulfetos (galena) e fosfatos (apatita). Os sedimentos de Mato Preto apresentaram teores mais altos de $\mathrm{FeO}^{\mathrm{T}}, \mathrm{MnO}, \mathrm{F}, \mathrm{As}, \mathrm{Cu}, \mathrm{Nb}, \mathrm{Pb}, \mathrm{Rb}$, Th, e Y com relação às demais amostras, correspondentes aos enriquecimentos em fluorita, magnetita, apatita, pirita, bornita e minerais de ETR.

Algumas fases minerais que possivelmente aportam o flúor aos sedimentos seriam hornblenda, illita e esmectita, identificadas por DRX. Nos difratogramas das amostras próximas às áreas mineralizadas não foram identificados os picos da fluorita, o que deve ser devido ao fato de que, nas condições experimentais da análise de difração não são detectadas as fases com concentração menor do 1-2 \% em peso. Por este motivo, estas amostras foram também observadas ao MEV, tendo sido constatada a presença da fluorita mediante a realização de mapeamento de elementos por meio de imagens de elétrons retro-espalhados. Outras fases minerais identificadas foram apatita (provavelmente fluorapatita), barita, biotita, zircão, rutilo, ilmenita, quartzo, feldspatos e óxidos de ferro.

CONCLUSÕES Com relação à qualidade das águas superficiais da região de Cerro Azul, este estudo revelou uma área de risco, localizada nas proximidades da jazida Mato Preto, cujas águas não são adequadas para consumo humano devido às altas concentrações de fluoreto. Por outra parte, foi constatado que os teores de $\mathrm{F}^{-}$nas águas distribuídas para consumo na cidade de Cerro Azul e no povoado de Mato Preto foram inferiores ao estabelecido pela legislação.

No caso dos sedimentos de corrente, a fração $<63 \mu \mathrm{m}$ caracterizou-se por apresentar, em geral, teores mais elevados de F do que $\mathrm{a}<177 \mu \mathrm{m}$, podendo se explicar isto pela retenção de flúor em minerais de argila (illita e esmectita principalmente) que estão contidas nesta fração granulométrica, além da fluorita, que, dada sua fragilidade é mais concentrada na fração mais fina. De acordo com a composição mineralógica das rochas da região e dos sedimentos fluviais, as possíveis fontes do F nos sedimentos seriam fluorita e apatita (provavelmente fluorapatita) provenientes das áreas mineralizadas, hornblendas e biotitas (e acessórios como apatita e titanita) das rochas graníticas, e illita e esmectitas resultantes da alteração dos diferentes minerais e a partir dos meta-sedimentos síltico-argilosos do Grupo Açungui.

As correlações obtidas entre $\mathrm{F}^{-}$e outros elementos nas águas superficiais permitiram inferir que este elemento, quando em baixos teores e não associado à mineralização de $\mathrm{CaF}_{2}$, poderia ser proveniente da alteração de silicatos como biotita e hornblenda, e ainda da solubilização de fluorita. Também as correlações com elementos como $\mathrm{Ca}^{2+}, \mathrm{Sr}^{2+}, \mathrm{Li}^{+}$e $\mathrm{K}^{+}$, mostram a associação dos depósitos de fluorita com as rochas carbonáticas e alcalinocarbonatíticas da área. 

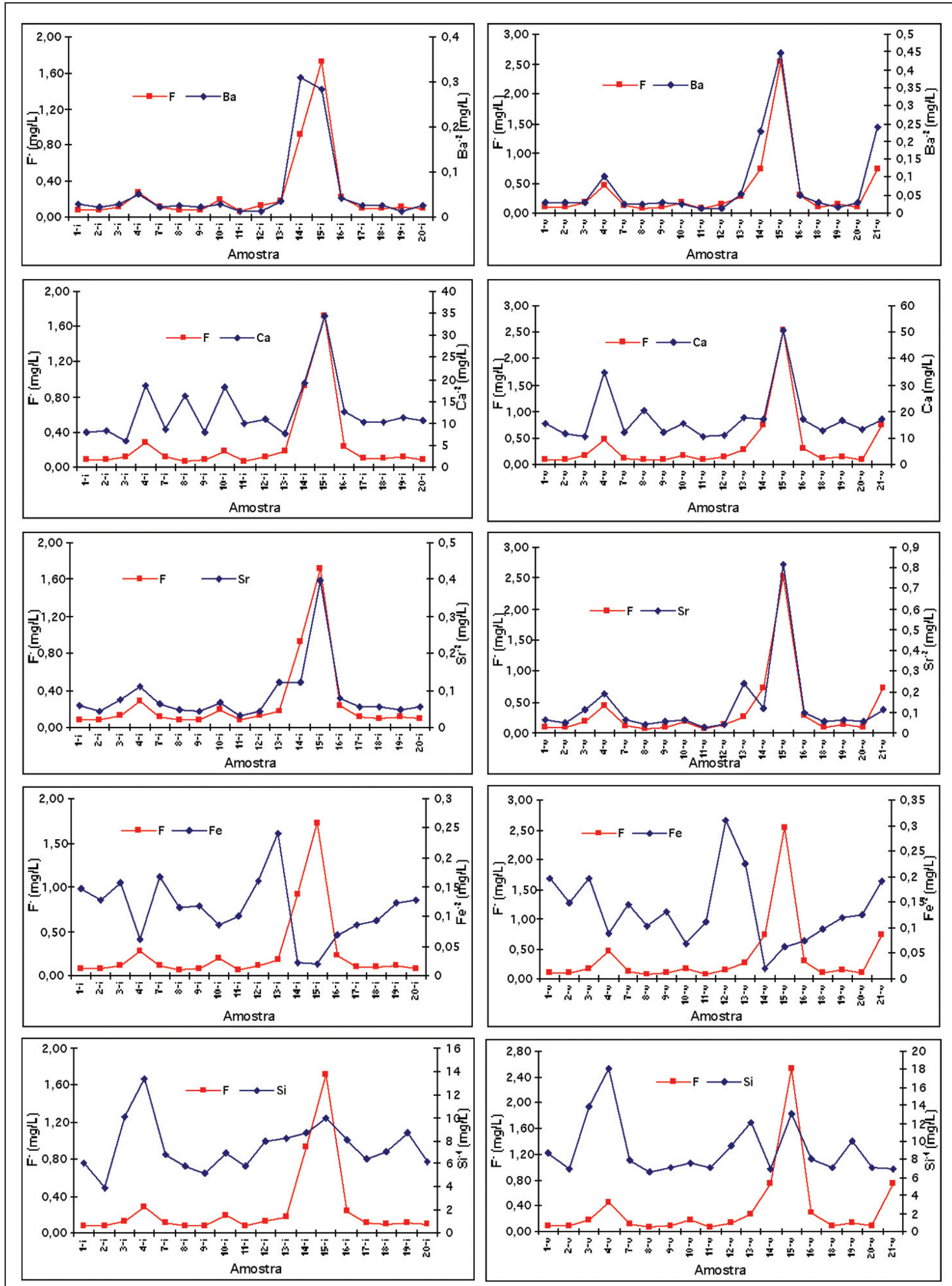

Figura 4. Concentrações de F versus concentrações de Ca, Ba, Sr e Fe em água superficial (gráficos da esquerda para julho/03 e da direita para março/04). 


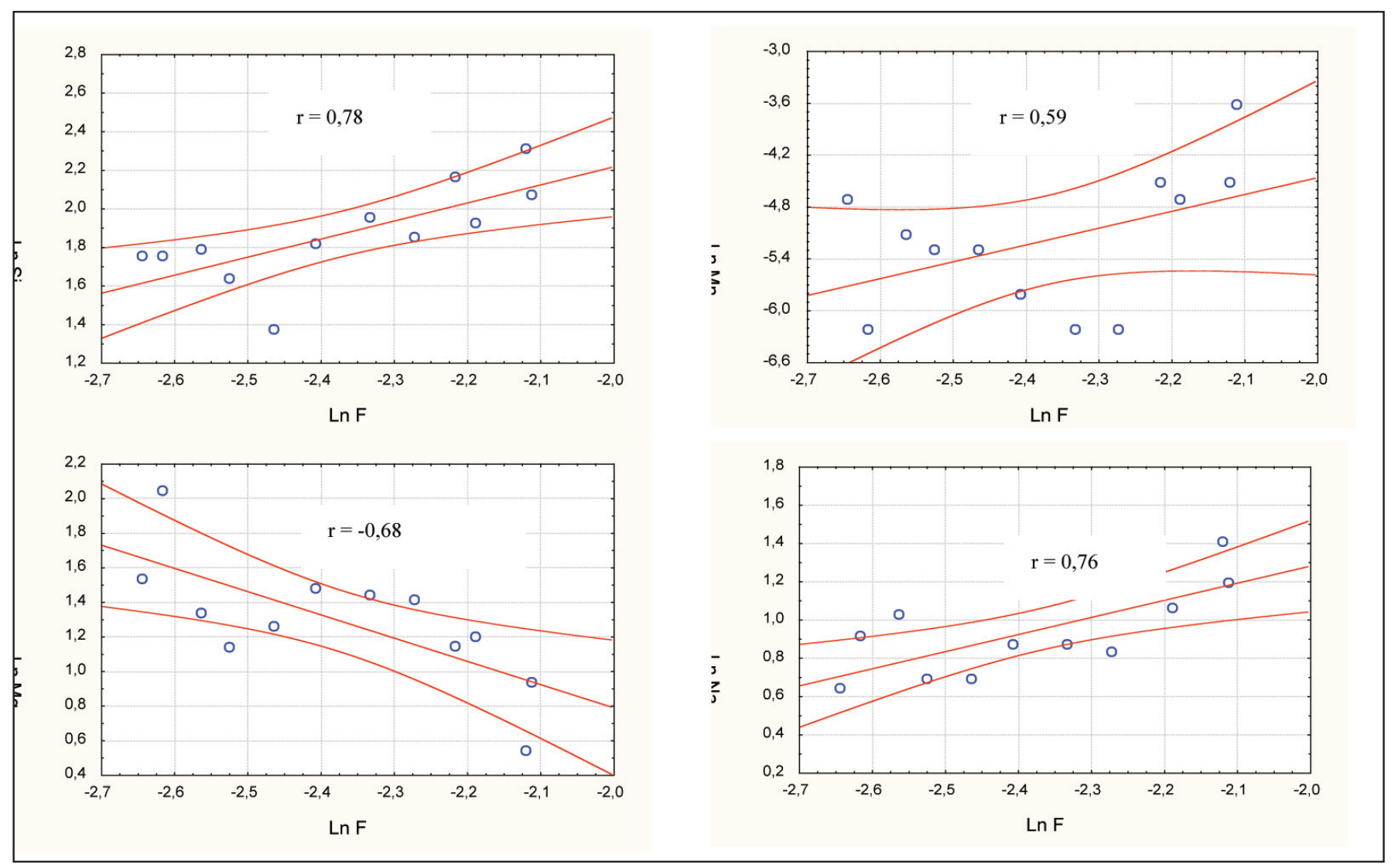

Figura 5. Gráficos das correlações do F versus Si, Mn, Mg e Na nas amostras de água superficial de julho/03 (N=12). Valores transformados em Ln.

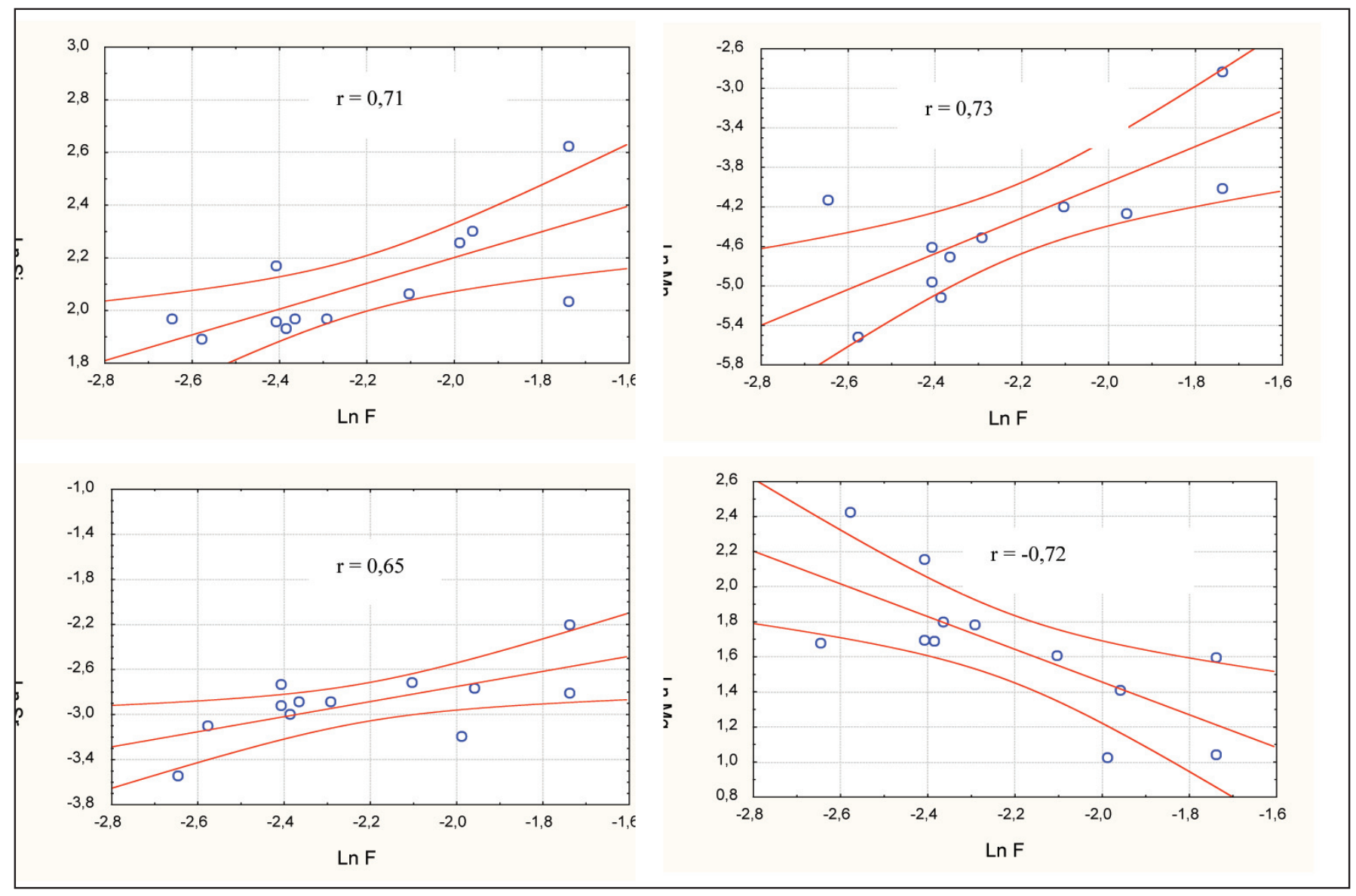

Figura 6. Gráficos das correlações do F versus Si, Mn, Sr e Mg nas amostras de água superficial de março/04 (N=12). Valores transformados em Ln. 
Se bem os resultados mostrem que o risco de exposição da população ao fluoreto a partir das águas superficiais é baixo, suspeita-se que os teores de fluoreto nas águas subterrâneas sejam maiores, dado o maior tempo de interação das águas com as formações rochosas. A amostra de água de poço (23), pertencente ao ambiente granítico, apresentou um teor próximo a $1 \mathrm{mg} / \mathrm{L} \mathrm{F}^{-}$, e especial interesse merecem as águas dos aqǘferos localizados nas rochas carbonáticas e alcalino-carbonatíticas, visto que nelas foram registrados os maiores teores de $\mathrm{F}^{-}$em

Tabela 2. Teores de flúor em sedimentos de corrente.

\begin{tabular}{|c|c|c|c|c|c|}
\hline \multirow{2}{*}{ Amostra } & \multicolumn{2}{|c|}{$\mathbf{F}(\boldsymbol{\mu g} / \mathbf{g})$} & \multirow{2}{*}{ Amostra } & \multicolumn{2}{c|}{$\mathbf{F}(\boldsymbol{\mu g} / \mathbf{g})$} \\
\cline { 2 - 5 } & $<\mathbf{1 7 7} \boldsymbol{\mu m}$ & $<\mathbf{6 3} \boldsymbol{\mu m}$ & & $<\mathbf{1 7 7} \boldsymbol{\mu m}$ & $<\mathbf{6 3} \boldsymbol{\mu m}$ \\
\hline $\mathbf{1}$ & 342 & 540 & $\mathbf{9}$ & 504 & 640 \\
\hline $\mathbf{2}$ & 546 & 574 & $\mathbf{1 0}$ & 380 & 590 \\
\hline $\mathbf{3}$ & 544 & 800 & $\mathbf{1 1}$ & 330 & 472 \\
\hline $\mathbf{4 a}$ & 994 & 1052 & $\mathbf{1 5 a}$ & 1125 & 896 \\
\hline 4b & 980 & 1080 & $\mathbf{1 5 b}$ & 1300 & 1240 \\
\hline $\mathbf{7}$ & 534 & 620 & $\mathbf{1 9}$ & 440 & 480 \\
\hline $\mathbf{8}$ & 340 & 440 & $\mathbf{2 0}$ & 470 & 548 \\
\hline
\end{tabular}

águas superficiais.

Portanto, no caso da existência de pessoas que possam estar bebendo água subterrânea de poços particulares, recomendase a análise prévia dessas águas para $\mathrm{F}^{-} \mathrm{e}$ a avaliação de risco. Resulta de interesse também a determinação dos conteúdos de flúor nos solos, e em alguns cultivos da região, os quais podem estar constituindo outra fonte de ingestão de flúor via alimentação, e aumentando o risco de fluorose nessas populações.

Agradecimentos. Ao Conselho Nacional de Pesquisa CNPq e Fapesp (Proc. $\mathrm{N}^{\circ}$ 02/0271-0) pelo financiamento desta pesquisa. Aos diretores da empresa Mineração Nossa Sra. do Carmo Ltda., pela autorização ao acesso às minas e o apoio importante durante os trabalhos de campo. À empresa Mineropar pelo acesso à documentação geológica da área de estudo. Ao Geol. Ídio Lopes Jr (CPRM-SP) e colaboradores pelo apoio de campo. Ao Laboratório de Análises Minerais (LAMIN) da CPRM, pelas análises das amostras de água. Ao Laboratório de Raios X do Centro de Geociências da Universidade Federal do Pará, pelas análises de DRX. À Companhia de Saneamento do Paraná (SANEPAR) pelas informações fornecidas e por permitir o uso das suas instalações em Cerro Azul. Aos técnicos Dailto Silva e Aparecida Vendemiatto do IG da Unicamp, pela ajuda com os dados de FRX e MEV.

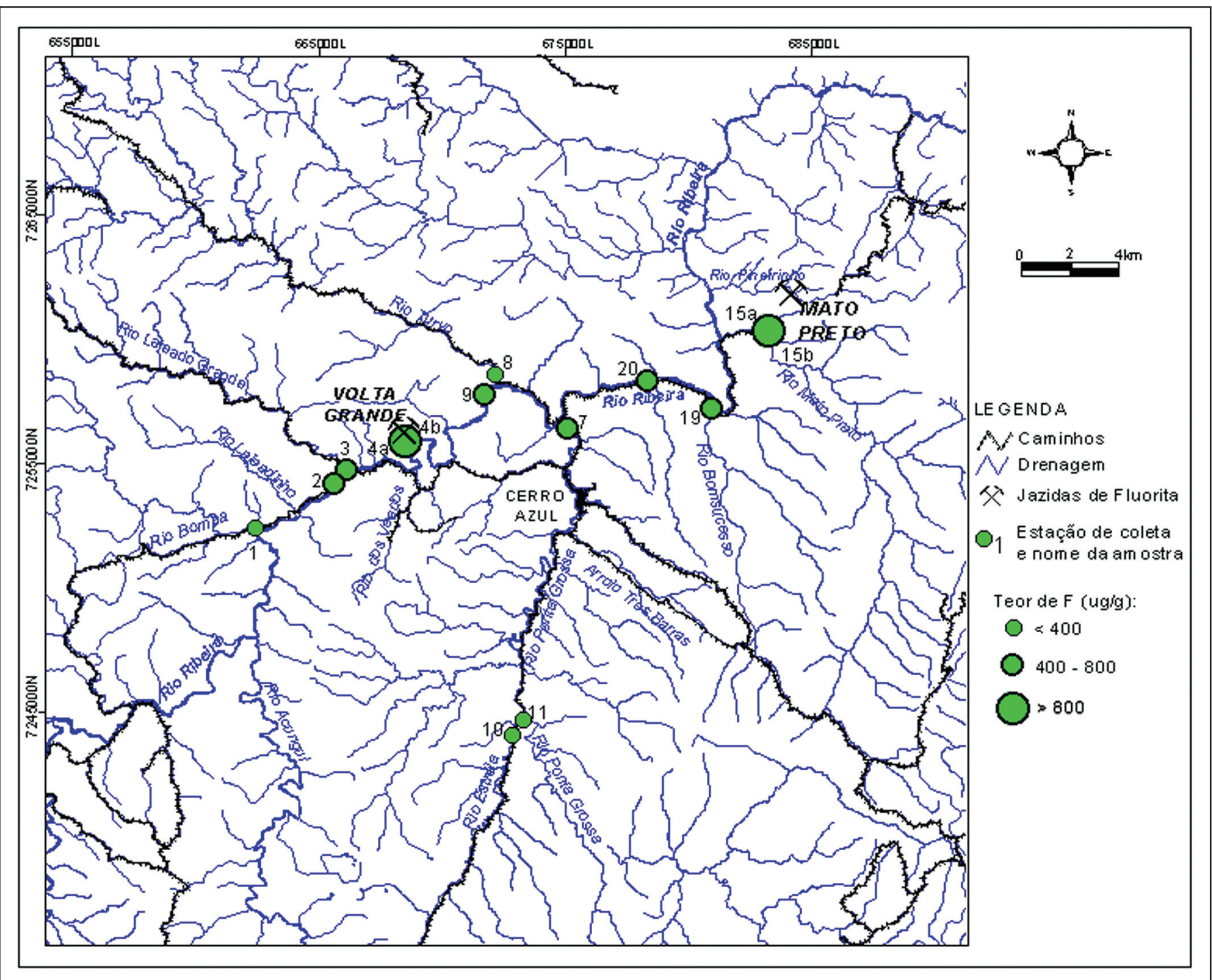

Figura 7. Mapa de teores de flúor em sedimentos de corrente (fração <177u). 


\section{Referências}

Allmann R. \& Koritning S. 1972. Fluorine. In: K.H. Wedepohl (Ed.) Handbook of Geochemistry. Springer Verlag. Berlin. Cap 9, 66 p.

Andrews-Jones D.A. 1968. Application of geochemical techniques to mineral exploration. Min. Ind. Bull. (Colorado School of Mines), 11(6) 1-31.

ANVISA 2004. Controle e vigilância da qualidade da água para consumo humano e seu padrão de potabilidade. Portaria $\mathrm{N}^{\circ} 518$, de 25 de março de 2004, Ministério da Saúde, Agência Nacional de Vigilância Sanitária, Brasília, 15 p.

Apambire W.B., Boyle D.R., Michel F.A. 1997. Geochemistry, genesis, and health implications of fluoriferous groundwaters in theupper regions of Ghana. Environmental Geology, 33(1):13-24.

ATSDR (Agency for Toxic Substances and Disease Registry) 2001. Toxicological profile for fluorides, hydrogen fluoride and fluorine. Disponível em: http://www.atsdr.cdc.gov/tfacts 11.html. Acesso: novembro/2004.

Bell F.G. 1998. Environmental Geology. Principles and Practice, Blackwell Science Ltd., 594 pp.

Blarasín M., Cabrera A., Paris M., Matteoda E. 2003. Aplicación del análisis factorial y cluster al tratamiento de datos hidrogeoquímicos en la hoja Río Cuarto, Córdoba. In: Congreso Argentino de Hidrogeología y I Seminario Hispano-Latinoamericano sobre temas actuales de la hidrología subterránea, 3, Rosario, Argentina, Memorias, Tomo 2, p. 309-318.

Bonorino A.G., Albouy R., Bundschuh J. 2002. Geoquímica y origen del flúor en el acuífero de la vertiente suroccidental de las Sierras Australes. In: International Association of Hidrogeologists IAH, 32, \& Associacion Lationoamericana de Hidrologia Subterrânea para el Desarollo ALHSUD, 6, Congress, Mar del Plata, Argentina, Memorias, p.126.

Cangussu M.C.T., Narvai P.C., Fernandez R.C., Djehizian V. 2002. A fluorose dentária no Brasil: uma revisão crítica. Cad. Saúde Públi$c a$, 18(1):7-15.

Cardoso L., Morita M.C., Alves J.C., Licht O.A.B. 2001. Anomalia hidrogeoquímica e ocorrência de fluorose dentária em ItambaracáPr. In: Congresso Brasileiro de Geoquímica, 8, Curitiba. Resumos, CD.

CONAMA (Conselho Nacional do Meio Ambiente) 1986. Resolução $\mathrm{n}^{\circ}$ 020/86. Disponível em: http: www.sosaguas.org.br/legislaçãoconama.htm. Acesso: Juno/2003.

Dardenne M. A, Ronchi L. H., Bastos Neto A. C., Touray J.C. 1997. Geologia da fluorita. In: C. Schobbenhaus, E. Teixeira de Queiroz, C.E. Silva Coelho (eds.) Principais Depósitos Minerais do Brasil. DNPM/CPRM, Brasília, Vol IV. Parte B. p. 479-506.

Darnley A.G, Bjorklund A., Bolviken B., Gustavsson N., Koval P.V., Plant J.A., Steenfelt A., Tauchid M., Xuejing X. 1995. A global geochemical database for environmental and resourse management: recommendations for international geochemical mapping - final report of IGCP project 259. United Nation Educational, Scientific and Cultural Organization (UNESCO), Paris, $122 \mathrm{p}$.

Finkelman R.B., Belkin H.E., Zheng B. 1999. Health impacts of domestic coal use in China. Proc. Natl. Acad. Sci. USA. 96:34273431.

Goldschmidt, V.T. 1970. Fluorine. In: A. Muir (ed.) Geochemistry. Clarendon, Oxford. p. 568-583.

Gupta S.K. \& Deshpande R.D. 1998. Depleting Groundwater Levels and Increasing Fluoride Concentration in Villages of Mehsana District, Gujarat, India: Cost to Economy and Health. Disponível em: http://www.globenet.org/preceup/pages/ang/chapitre/capitali/cas/ indmehs.htm. Acesso: maio/2004.

Huasi Y., Fonseca M.J.G., Ramalho R. 1984. A parte central da região de dobramentos sudeste e o maciço mediano de Guaxupé. In: Schobbenhaus et al. (eds.). Geologia do Brasil. Departamento Nacional da Produção Mineral, Brasília, Parte VII, p. 307-328.

Hurtado R., Gardea-Torresdey J., Tiemann K.J. 2000. Fluoride occur- rence in tap water at "Los Altos de Jalisco" in the Central Mexico Region. In: Proceedings of the 2000 Conference on Hazardous Waste Research, Atas, p. 211-219.

Jenkins R.E. 1987. Geology of the Clugger-Fluorite Deposit, Mato Preto, Paraná, Brazil. Rev. Brasileira. de Geociências, 17(3):288294.

Licht O.A.B. 2001. A geoquímica multielementar na gestão ambiental. Identificação e caracterização de províncias geoquímicas naturais, alterações antrópicas da paisagem, áreas favoráveis à prospecção mineral e regiões de risco para a saúde no estado do Paraná, Brasil. Tese de doutoramento, Universidade Federal do Paraná, Curitiba-Pr, $209 \mathrm{p}$.

Licht O.A.B., Morita M.C., Tarvainen T. 1996a. A utilização de dados de prospecção geoquímica de fluorita no primeiro planalto paranaense, na identificação de áreas de interesse para a saúde pública. Uma abordagem preliminar. Geoch. Brasil., 10:57-69.

Licht O.A.B., Arioli E.E., Piekarz G.F. 1996b. The multi-level geochemical survey in Paraná State, Brazil. In: International Geological Congress, 30, Beijing, Documents, CD.

Licht O.A.B., Piekarz G.F., da Silva J.C.C., Lopes Jr. I. 1997. Levantamento geoquímico multielementar de baixa densidade no Estado do Paraná (hidrogeoquímica - resultados preliminares). A terra em revista, 3(3):34-46.

Loureiro F.E.L. \& Tavares J.R. 1983. Duas novas ocorrências de carbonatitos: Mato Preto e Barra do Rio Itapirapuã. Revista Brasileira de Geociências 13(1):7-11.

OMS (Organização Mundial da Saúde) 1996. Disponível em: Http:// www.who.int/water_sanitation_health/ GDWQ/Chemicals/fluoridesum. Acesso: Juno/2003.

Meneasse L.N., Fantinel L.M., Knauer L.G., Horn A.H., Dupont H.S.J.B., Castro R.E.L., Freira A.P.S., Efigênia F., Paixão H.H., Castilho L., Bazzoli N., Santos C.V.N., Souza, C.A.S., Lúcio, P.S. 2002. Flúor na água subterrânea e fluorose dental no município de São Francisco, Minas Gerais. In: Congresso Brasileiro de Geologia, 41, João Pessoa, Anais, p. 554.

Orion 2001. Fluoride Eletrode Instruction Manual. Model 94-09, Model 96-09 ionplus. Thermo Orion. 46 p.

Ortiz Ruiz P. 1997. Efectos deletéreos de la administración oral de flúor. Revista de Medicina Interna Concepción, Chile, 1(2), Disponível em http://www2.udec.cl/ ofem/remedica/VOL2/fluor/fluor.htm.

Ronchi L.H., Felipe R.S., Dardenne M.A. 1987. O depósito de fluorita de Volta Grande: tipos de minério e sucessão mineral. In: Simpósio Sul-Brasileiro de Geologia, 3, Curitiba, Atas, Vol. 2, p. 615-622.

Ronchi L.H., Touray J.C., Dardenne M.A. 1995. Complex hydrothermal history of a roof pendant-hosted fluorite deposit at Volta Grande, Paraná (Southern Brazil). Economic Geology, 90:948-955.

SABESP (Secretaria de Saúde S. Paulo) 1996. Resolução SS-293/96. Disponível em: http:www.sabesp.com.br/legislacao/ PDF/ RSS29396.PDF. Acesso: Juno/2003.

Santos R.V. \& Dardenne M.A. 1988. Fluorita de Mato Preto: um caso particular de mineralização de fluorita associada a complexo alcalino carbonatítico. In: SBG, Congresso Brasileiro de Geologia, 35, Belém, Pará, Anais, Vol. 3, p. 1251-1261.

UNICEF 2003. UNICEF's position on water fluoridation. Disponível em: http: www.nofluoride.com/Unicef fluor.htm. Acesso: setembro 2003.

Warren C., Burgess W., Garcia M.G. 2002. Arsenic and fluoride in quaternary loess and alluvial aquifers at Los Pereyra, Tucumán, Argentina. In: International Association of Hidrogeologists IAH, 32, \& Associacion Lationoamericana de Hidrologia Subterranea para el Desarollo ALHSUD, 6, Congress 2002, Mar del Plata, Argentina, Memórias, p.91. 